\title{
Alterações Anatômicas foliares em Plantas de Brachiaria subquadripara SubMetidas à APLICAÇÃo DE HeRBICIdAs ${ }^{1}$
}

\author{
Anatomic Leaf Changes in Brachiaria subquadripara Submitted to Herbicide Application
}

\author{
COSTA, N.V. ${ }^{2}$, MARTINS, D. ${ }^{3}$, RODELLA, R.A. ${ }^{4}$ e RODRIGUES-COSTA, A.C.P. ${ }^{2}$
}

\begin{abstract}
RESUMO - O presente trabalho teve por objetivo avaliar a eficiência do controle dos herbicidas diquat, glyphosate e imazapyr e as alterações anatômicas do limbo foliar provocadas por eles em plantas de Brachiaria subquadripara. As plantas foram cultivadas em caixas-d'água sob condições de campo e, quando atingiram estádio de pleno desenvolvimento vegetativo, foram pulverizadas com soluções de diquat a $400 \mathrm{~g} \mathrm{ha}^{-1}$, glyphosate a $4.320 \mathrm{~g}^{\text {ha-1 }}$ em associação com o adjuvante Aterbane a $0,5 \% \mathrm{v} \mathrm{v}^{-1}$ e imazapyr a $750 \mathrm{~g} \mathrm{ha}^{-1}$. Além disso, utilizou-se uma testemunha sem aplicação de herbicida. Foram realizadas avaliações de controle e das seguintes características anatômicas quantitativas das regiões da nervura central e da internervural do limbo foliar, além da região do colmo: porcentagem da epiderme adaxial e abaxial, porcentagem da endoderme, porcentagem do feixe vascular, porcentagem de lacunas do aerênquima, porcentagem de parênquima, espessura foliar, porcentagem da epiderme do colmo, porcentagem do câmbio vascular e diâmetro do colmo. Os herbicidas diquat e imazapyr promoveram o maior número de alterações nos caracteres anatômicos quantitativos das regiões da nervura central e internervural do limbo foliar e da região do colmo das plantas. Contudo, com exceção do diquat, os herbicidas foram eficientes no controle das plantas de B. subquadripara, porém todos eles permitiram a rebrota delas.
\end{abstract}

Palavras-chave: anatomia foliar, planta aquática, planta daninha, controle químico.

\begin{abstract}
The aim of this work was to evaluate the control efficacy of diquat, glyphosate, and imazapyr and the anatomic leaf blade changes caused by these herbicides in $\boldsymbol{B}$. subquadripara. The plants were grown in reservoirs under field conditions, and, after reaching the full vegetative development stage, were sprayed with solutions of diquat at $400 \mathrm{~g} \mathrm{ha}^{-1}$, glyphosate at 4,320 $\mathrm{g} \mathrm{ha}^{-1}$ combined with Aterbane at $0.5 \% v v^{1}$, and imazapyr at $750 \mathrm{~g} \mathrm{ha}^{-1}$. A control without herbicide was used. Control evaluations were carried out, followed by evaluation of the anatomic quantitative characteristics of the central vein and intervein regions of the leaf blade, as well as of the stem region: adaxial and abaxial epidermis \%, endoderm \%, vascular bundle \%, aerenchyma lacunas \%, parenchyma and leafthickness $\%$, epidermal stem $\%$, and vascular cambium and stem diameter $\%$. The herbicides diquat and imazapyr promoted the largest number of changes in the quantitative anatomic characters of the midrib and intervein regions of the leaf and stem regions of the plants. However, with the exception of diquat, the herbicides were effective in controlling the B. subquadripara plants. All the herbicides allowed plant re-growth.
\end{abstract}

Keywords: leaf anatomy, aquatic plant, weed, chemical control

\section{INTRODUÇÃO}

A vegetação aquática apresenta importantes funções para a manutenção do equilíbrio do ambiente em que vive, como na proteção e estabilização das margens de rios, lagos e represas, diminuindo os efeitos erosivos da água; é fundamental também na cadeia

1 Recebido para publicação em 12.12.2011 e aprovado em 12.3.2012.

2 Professor Adjunto, Centro de Ciências Agrárias, Universidade Estadual do Oeste do Paraná, Marechal Cândido Rondon-PR, <neumarciovc@hotmail.com>; ${ }^{3}$ Professor Livre Docente, Dep. de Produção Vegetal, Faculdade de Ciências Agronômicas, Universidade Estadual Paulista "Júlio de Mesquita Filho" - FCA/UNESP, Fazenda Lageado, Caixa Postal 237, $18603-970$ BotucatuSP, ${ }^{4}$ Professor Dr., Dep. de Botânica, Instituto de Biociências de Botucatu/UNESP, Botucatu-SP. 
alimentar, promovendo a oxigenação e a depuração da água. Entretanto, alterações no ambiente, seja pela mudança na qualidade da água e/ou pela construção de reservatórios, alterando os niveis hidrométricos do ecossistema, podem acarretar o desenvolvimento indesejado das populações de plantas aquáticas e ocasionar prejuízos significativos ao ambiente, bem como ao uso múltiplo da água (Tanaka, 2001).

Do ponto de vista ambiental, algumas espécies de crescimento rápido podem suprimir outras menos agressivas, desejáveis para manutenção da diversidade, ou modificar negativamente algumas características físicas da água (Cardoso et al., 2002). O lançamento de efluentes de origem urbana e industrial, além do aporte de fertilizantes utilizados na agricultura, para os corpos hídricos podem ser citados como outras possiveis causas que estimulam a proliferação desordenada das espécies de plantas aquáticas.

Dessa maneira, em levantamento das comunidades infestantes observadas nos reservatórios de hidrelétricas de cinco bacias hidrográficas do Estado de São Paulo foram identificadas 39 espécies, distribuídas em 21 familias, destacando-se a emersa $B$. subquadripara, considerando as quatro espécies com maior frequência em cada bacia (Martins et al., 2008).

Os métodos de controle de plantas aquáticas mais adotados normalmente são o biológico, químico e mecânico. Entre estes, destacase o controle químico como a alternativa mais econômica, além de ser eficiente. Vários trabalhos realizados por diferentes pesquisadores têm comprovado a eficiência do controle químico e a sua segurança sobre os organismos aquáticos por meio do uso de diversos herbicidas (Murphy \& Barrett, 1990; Hofstra et al., 2001; Parsons et al., 2001).

Segundo Procópio et al. (2003), a morfologia das plantas, principalmente das folhas, influencia na quantidade do herbicida interceptado e retido. Contudo, é a anatomia das folhas que praticamente determina a facilidade com que esses produtos serão absorvidos; assim, o estudo anatômico de folhas pode melhorar o entendimento sobre as barreiras que cada espécie impõe à absorção dos herbicidas e, dessa maneira, fornecer subsídios para a busca de estratégias que superem esses obstáculos.

Dessa forma, a análise anatômica foliar pode ser aplicada com sucesso na identificação de espécies suscetíveis, tolerantes ou resistentes a determinado produto químico, assim como na descrição dos sintomas fitotóxicos, contribuindo com os estudos de seletividade de herbicidas a espécies terrestres ou aquáticas.

O presente trabalho teve por objetivos avaliar a eficiência dos herbicidas diquat, glyphosate e imazapyr no controle de plantas de $B$. subquadripara, bem como as prováveis alterações anatômicas do limbo foliar proporcionadas por eles.

\section{MATERIAL E MÉTODOS}

O experimento foi conduzido no Núcleo de Pesquisas Avançadas em Matologia - NUPAM, do Departamento de Produção Vegetal, pertencente à Faculdade de Ciências Agronômicas de Botucatu/UNESP, e no Departamento de Botânica do Instituto de Biociências de Botucatu/UNESP. O local do experimento apresenta as seguintes coordenadas geográficas: latitude de $22^{\circ} 07^{\prime} 56^{\prime \prime} \mathrm{S}$, longitude de $74^{\circ} 66^{\prime} 84^{\prime}$ W Gr. e altitude de $762 \mathrm{~m}$.

Foram avaliadas plantas de $B$. subquadripara coletadas nos reservatórios do complexo CESP do Estado de São Paulo e reproduzidas por meio de suas estruturas de dispersão vegetativa, acondicionadas em pleno sol, em caixas-d'água de fibra de vidro de 350 litros, contendo uma camada de $30 \mathrm{~cm}$ de solo no fundo. Os herbicidas foram aplicados em pós-emergência, quando as plantas atingiram pleno desenvolvimento vegetativo (antes do florescimento), utilizando-se um pulverizador costal, pressurizado por $\mathrm{CO}_{2} \mathrm{e}$ equipado com um reservatório de 2 litros.

$\mathrm{O}$ equipamento foi regulado para proporcionar consumo de calda de $200 \mathrm{~L} \mathrm{ha}^{-1}$. A barra de aplicação foi equipada com duas pontas tipo jato plano Teejet XR 110.02, distanciadas $50 \mathrm{~cm}$ entre si. Os tratamentos utilizados foram os herbicidas diquat $\left(400 \mathrm{~g} \mathrm{ha}^{-1}\right.$ do produto comercial Reward), glyphosate (4.320 $\mathrm{g} \mathrm{ha}^{-1}$ do produto comercial Rodeo) com a adição do adjuvante Aterbane na concentração 
do produto comercial de $0,5 \% \mathrm{v} \mathrm{v}^{-1}$ e imazapyr (750 $\mathrm{g} \mathrm{ha}^{-1}$ do produto comercial Arsenal), além de uma testemunha sem aplicação. Foram realizadas avaliações de controle após $1,3,10$, 30, 63, 98 e 226 dias após a aplicação (DAA) dos produtos.

As avaliações de controle foram visuais, utilizando-se escala percentual de notas, em que 0 corresponde a nenhuma injúria demonstrada pela planta e 100 à morte das plantas, de acordo com a metodologia proposta pela Sociedade Brasileira da Ciência das Plantas Daninhas (SBCPD, 1995). Os parâmetros utilizados para o estabelecimento das notas foram: quantidade de plantas mortas, inibição do crescimento, quantidade e uniformidade das injúrias e capacidade de rebrota das plantas.

Para os estudos anatômicos, nas datas de 1 e 16 DAA, foram coletadas porções da região mediana do limbo foliar das plantas que apresentaram sintomas externos de intoxicação e da testemunha. Foram tomadas as porções do terço médio do limbo foliar, compreendendo as regiões da nervura central e internervural (situada entre a nervura central e o bordo do limbo foliar), fixando-as em FAA 50 (formaldeído + ácido acético glacial + álcool 50\%) durante 48 horas, sendo, posteriormente, conservadas em álcool 70\% (Johansen, 1940), utilizando-se quatro repetições.

As amostras do material foliar foram desidratadas em série etílica ascendente e, em seguida, infiltradas em resina glicolmetacrilato, seguindo-se a técnica de Gerrits (1991). Realizaram-se cortes transversais com espessura de 8 a $10 \mu \mathrm{m}$, utilizando micrótomo rotatório; os cortes foram submetidos à coloração com Azul de Toluidina 0,05\% (O’Brien et al., 1964) e montados em resina sintética.

Para a quantificação das estruturas anatômicas das regiões da nervura central e internervural do limbo foliar, os limites e os contornos dos tecidos foram desenhados com o auxílio de microscópio de projeção e as mensurações feitas com auxílio de mesa digitalizadora acoplada a um computador equipado com o programa de Sistema de Planimetria (SPLAN), desenvolvido pelo CINAG - UNESP.

Foram avaliadas as seguintes características anatômicas quantitativas das regiões da nervura central e internervural do limbo foliar: porcentagem da epiderme adaxial e abaxial, porcentagem da endoderme, porcentagem do feixe vascular, porcentagem de esclerênquima, porcentagem de parênquima e espessura foliar $(\mu \mathrm{m})$; e, na região do colmo: porcentagem da epiderme, porcentagem do câmbio vascular, porcentagem do feixe vascular, porcentagem de lacunas do aerênquima, porcentagem de parênquima e diâmetro do colmo $(\mathrm{mm})$.

Os tratamentos foram dispostos em delineamento experimental inteiramente casualizado; para as avaliações das alterações anatômicas do limbo foliar foi adotado esquema fatorial $4 \times 2$ ( 4 herbicidas $\times 2$ épocas de avaliações), com quatro repetições. Os dados de controle e das alterações anatômicas do limbo foliar foram analisados estatisticamente, empregando-se o teste LSD a $5 \%$ de probabilidade; os dados originais expressos em porcentagem foram transformados, utilizando-se arco seno $\sqrt{ } \mathrm{x} / 100$ (PimentelGomes, 1976).

\section{RESULTADOS E DISCUSSÃO}

A porcentagem de controle proporcionada pelos herbicidas diquat, glyphosate e imazapyr em plantas de $B$. subquadripara está apresentada na Tabela 1. Verificou-se que a partir de 1 DAA o diquat foi o herbicida que promoveu a maior nota de controle das plantas $(33,0 \%)$, em relação à testemunha. Aos 10 DAA, apenas o glyphosate mostrou controle acima de $90,0 \%$, ao passo que as plantas apresentaram rebrotamento quando tratadas com diquat.

Somente o glyphosate e o imazapyr mostraram controle de 98,8 e 93,3\% aos 63 DAA, respectivamente. Esses resultados persistiram até os 98 DAA, porém aos 226 DAA as plantas tratadas com o glyphosate e o imazapyr apresentaram rebrota, reduzindo o controle a 57,5 e 90,0\%, respectivamente. Assim, esse fato evidencia que, apesar da elevada eficiência apresentada por esses herbicidas no controle de $B$. subquadripara, torna-se importante a realização de monitoramento constante nas áreas aplicadas, a fim de que se possa avaliar a necessidade de uma reaplicação e evitar a reinfestação do local (Costa et al., 2011). 
Destaca-se que esses resultados corroboram os obtidos por Carbonari et al. (2003), que avaliaram os efeitos dos herbicidas diquat, glyphosate e imazapyr no controle de $B$. subquadripara e concluíram que o glyphosate ( 3.360 e $4.320 \mathrm{~g} \mathrm{ha}^{-1}$ ) proporcionou controle excelente $(>99,0 \%)$, o imazapyr (750 e $\left.1.500 \mathrm{~g} \mathrm{ha}^{-1}\right)$, controle satisfatório $(95,0 \mathrm{a}$ $98,0 \%$ ), enquanto o diquat mostrou-se ineficiente no controle aos 75 DAA.

Na Tabela 2 são apresentados os valores do teste $\mathrm{F}$ e do coeficiente de variação dos caracteres anatômicos quantitativos das regiões da nervura central e internervural do limbo foliar e do colmo de plantas de $B$. subquadripara.

Na Tabela 3 podem-se verificar os valores médios dos caracteres anatômicos quantitativos da região da nervura central do limbo foliar das plantas de $B$. subquadripara. Observou-se que apenas os caracteres porcentagem da epiderme adaxial e esclerênquima não apresentaram interação entre os fatores herbicidas e época de avaliação (Tabelas 2 e 3). O caractere porcentagem da epiderme adaxial

Tabela 1 - Porcentagem de controle das plantas de B. subquadripara após a aplicação dos herbicidas. Botucatu-SP, 2005

\begin{tabular}{|c|c|c|c|c|c|c|c|c|}
\hline \multirow{2}{*}{ Tratamento } & \multirow{2}{*}{$\frac{\text { Dose }}{\left(\mathrm{g} \mathrm{ha}^{-1}\right)}$} & \multicolumn{7}{|c|}{ Dias após a aplicação } \\
\hline & & 1 & 3 & 10 & 30 & 63 & 98 & 226 \\
\hline Testemunha & 1 & $0,0(0,0) \mathrm{c}$ & $0,0(0,0) \mathrm{c}$ & $0,0(0,0) \mathrm{c}$ & $0,0(0,0) \mathrm{c}$ & $0,0(0,0) \mathrm{c}$ & $0,0(0,0) \mathrm{c}$ & $0,0(0,0) \mathrm{c}$ \\
\hline Diquat & 400 & $33,0(35,1) \mathrm{a}$ & $43,8(41,4) \mathrm{a}$ & $7,8(16,1) \mathrm{b}$ & $0,0(0,0) \mathrm{c}$ & $0,0(0,0) \mathrm{c}$ & $0,0(0,0) \mathrm{c}$ & $0,0(0,0) \mathrm{c}$ \\
\hline $\begin{array}{l}\text { Glyphosate + } \\
\text { Aterbane }\end{array}$ & $4.320+0,5 \mathrm{v} \mathrm{v}^{-1}$ & $10,5(18,9) b$ & $41,3(40,0) \mathrm{a}$ & $97,3(80,6)$ a & $99,5(88,0) \mathrm{a}$ & $98,8(85,7) \mathrm{a}$ & $97,0(83,4) \mathrm{a}$ & $57,5(56,3)$ a \\
\hline Imazapyr & 750 & $0,0(0,0) \mathrm{c}$ & $1,5(6,9) b$ & $7,8(16,1) \mathrm{b}$ & $66,3(54,7) \mathrm{b}$ & $93,3(75,2) \mathrm{b}$ & $95,0(77,6) \mathrm{b}$ & $90,0(74,1) \mathrm{a}$ \\
\hline $\mathrm{F}_{\text {Tratamento }}$ & & $1.482,169^{* *}$ & $1.075,615^{* *}$ & $2.209,936^{* *}$ & $572,632 * *$ & $934,304 * *$ & $358,217^{* *}$ & $14,203^{* *}$ \\
\hline $\mathrm{CV}(\%)$ & & 6,51 & 5,99 & 5,39 & 10,16 & 7,59 & 12,22 & 62,42 \\
\hline d.m.s. & & 1,353 & 2,068 & 2,342 & 5,584 & 4,701 & 7,576 & 31,35 \\
\hline
\end{tabular}

Os dados originais de porcentagem foram transformados em arco seno $\sqrt{ } \mathrm{x} / 100$, entre parênteses. Médias seguidas de mesma letra minúscula na coluna não diferem estatisticamente entre si a $5 \%$ de probabilidade pelo teste LSD. ${ }^{* *}$ significativo a $1 \%$ de probabilidade.

Tabela 2 - Valores do teste F e do coeficiente de variação dos caracteres anatômicos quantitativos das regiões da nervura central e internervural do limbo foliar e do colmo das plantas de B. subquadripara. Botucatu-SP, 2005

\begin{tabular}{|c|c|c|c|c|c|c|c|}
\hline Fonte de variação & $\begin{array}{c}\% \text { Epiderme } \\
\text { adaxial }\end{array}$ & $\begin{array}{l}\text { \% Epiderme } \\
\text { abaxial }\end{array}$ & $\%$ Endoderme & $\begin{array}{l}\% \text { Feixe } \\
\text { vascular }\end{array}$ & \% Esclerênquina & \% Parênquima & $\begin{array}{r}\text { Espessura } \\
\text { foliar }(\mu \mathrm{m})\end{array}$ \\
\hline & \multicolumn{7}{|c|}{ Região da nervura central } \\
\hline Herbicidas $(\mathrm{H})$ & $3,219 *$ & $3,563 *$ & $3,884 *$ & $12,231 * *$ & $5,708 * *$ & $8,926^{* *}$ & $5,233^{* *}$ \\
\hline Época de Avaliação (E) & $1,301 \mathrm{~ns}$ & $8,319 * *$ & $2,927 \mathrm{~ns}$ & $18,578^{* *}$ & $2,886 \mathrm{~ns}$ & $1,772 \mathrm{~ns}$ & $10,460 * *$ \\
\hline$(\mathrm{H}) \times(\mathrm{E})$ & $0,288 \mathrm{~ns}$ & $7,078 * *$ & $3,152 *$ & $8,427 * *$ & $2,384 \mathrm{~ns}$ & $3,510 *$ & $6,194 * *$ \\
\hline \multirow[t]{2}{*}{$\mathrm{CV}(\%)$} & 16,40 & 5,80 & 5,76 & 6,50 & 14,21 & 6,93 & 12,76 \\
\hline & \multicolumn{7}{|c|}{ Região internervural } \\
\hline Herbicidas $(\mathrm{H})$ & $1,610 \mathrm{~ns}$ & $2,665 \mathrm{~ns}$ & $0,242 \mathrm{~ns}$ & $3,204 *$ & $2,521 \mathrm{~ns}$ & $2,435 \mathrm{~ns}$ & $3,658^{*}$ \\
\hline Época de Avaliação (E) & $0,699 \mathrm{~ns}$ & $19,830 * *$ & $0,781 \mathrm{~ns}$ & $19,919^{* *}$ & $2,413 n s$ & $16,527 * *$ & $22,089 * *$ \\
\hline$(\mathrm{H}) \times(\mathrm{E})$ & $0,215 \mathrm{~ns}$ & $5,322 * *$ & $0,580 \mathrm{~ns}$ & $7,925^{* *}$ & $6,180^{* *}$ & $6,855^{* *}$ & $7,409 * *$ \\
\hline $\mathrm{CV}(\%)$ & 5,25 & 6,36 & 3,21 & 7,41 & 10,03 & 3,29 & 9,81 \\
\hline \multirow[t]{2}{*}{ Fonte de variação } & $\%$ Epiderme & $\begin{array}{l}\text { \% Câmbio } \\
\text { vascular }\end{array}$ & $\begin{array}{l}\% \text { Feixe } \\
\text { vascular }\end{array}$ & $\begin{array}{c}\% \text { Lacunas do } \\
\text { aerênquina }\end{array}$ & \% Parênquima & $\begin{array}{l}\text { Diâmetro do } \\
\text { colmo (mm) }\end{array}$ & \\
\hline & \multicolumn{7}{|c|}{ Região do colmo } \\
\hline Herbicidas $(\mathrm{H})$ & $2,194 \mathrm{~ns}$ & $2,777 \mathrm{~ns}$ & $4,796^{* *}$ & $2,466 \mathrm{~ns}$ & $6,119^{* *}$ & $0,889 \mathrm{~ns}$ & \\
\hline Época de Avaliação (E) & $8,880 * *$ & $3,514 \mathrm{~ns}$ & $5,999^{*}$ & $0,101 \mathrm{~ns}$ & $12,231^{* *}$ & $1,407 \mathrm{~ns}$ & \\
\hline$(\mathrm{H}) \times(\mathrm{E})$ & $0,510 \mathrm{~ns}$ & $2,174 \mathrm{~ns}$ & $4,081 *$ & $3,432 *$ & $2,307 \mathrm{~ns}$ & $0,923 \mathrm{~ns}$ & \\
\hline $\mathrm{CV}(\%)$ & 7,11 & 13,99 & 7,22 & 17,56 & 18,55 & 11,68 & \\
\hline
\end{tabular}

** significativo a $1 \%$ de probabilidade; * significativo a $5 \%$ de probabilidade; ${ }^{\text {ns }}$ não significativo. 
Tabela 3 - Valores médios dos caracteres anatômicos quantitativos da região da nervura central do limbo foliar das plantas de B. subquadripara. Botucatu-SP, 2005

\begin{tabular}{|c|c|c|c|c|c|}
\hline \multirow{2}{*}{$\mathrm{DAA}^{1 /}$} & \multicolumn{4}{|c|}{ Herbicida } & \multirow{2}{*}{ Média } \\
\hline & Testemunha & Diquat & Glyphosate & Imazapyr & \\
\hline & \multicolumn{4}{|c|}{$\%$ Epiderme adaxial } & \\
\hline 1 & $9,42(17,82)$ & $9,12(17,39)$ & $8,34(16,62)$ & $6,35(14,38)$ & $8,31(16,55)$ \\
\hline 16 & $11,51(19,55)$ & $9,07(17,50)$ & $10,68(18,94)$ & $6,58(14,75)$ & $9,46(17,68)$ \\
\hline \multirow[t]{2}{*}{ Média } & $10,46(18,69) \mathrm{a}$ & $9,09(17,44) \mathrm{ab}$ & $9,51(17,78) \mathrm{a}$ & $6,47(14,57) b$ & \\
\hline & \multicolumn{4}{|c|}{$\%$ Epiderme abaxial } & \\
\hline 1 & $4,35(12,03) \mathrm{bB}$ & $5,73(13,80)$ aA & $4,26(11,90) \mathrm{bB}$ & $4,74(12,57) \mathrm{bA}$ & $4,77(12,58)$ \\
\hline 16 & $5,44(13,47) \mathrm{aA}$ & $5,32(13,33)$ aA & $6,15(14,34)$ aA & $4,50(12,23) \mathrm{bA}$ & $5,35(13,34)$ \\
\hline \multirow[t]{2}{*}{ Média } & $4,89(12,75)$ & $5,53(13,57)$ & $5,21(13,12)$ & $4,62(12,40)$ & \\
\hline & \multicolumn{4}{|c|}{$\%$ Endoderme } & \\
\hline 1 & $31,15(33,92)$ aA & $30,73(33,60)$ aA & $26,21(30,77) \mathrm{bA}$ & $27,60(31,69) \mathrm{abA}$ & $28,92(32,50)$ \\
\hline 16 & $25,31(30,20) \mathrm{bcB}$ & $30,73(33,60) \mathrm{aA}$ & $28,45(32,22) \mathrm{abA}$ & $24,29(29,46) \mathrm{cA}$ & $27,19(31,38)$ \\
\hline \multirow[t]{2}{*}{ Média } & $28,23(32,06)$ & $30,73(33,63)$ & $27,33(31,50)$ & $25,95(30,56)$ & \\
\hline & \multicolumn{4}{|c|}{$\%$ Feixe vascular } & \\
\hline 1 & $7,82(16,21) \mathrm{bB}$ & $11,07(19,40)$ aA & $7,51(15,87) \mathrm{bB}$ & $8,48(16,91) \mathrm{bA}$ & $8,72(17,10)$ \\
\hline 16 & $9,99(18,40) \mathrm{bA}$ & $12,06(20,31) \mathrm{aA}$ & $12,57(20,74) \mathrm{aA}$ & $7,70(16,08) \mathrm{cA}$ & $10,58(18,88)$ \\
\hline \multirow[t]{2}{*}{ Média } & $8,91(17,31)$ & $11,56(19,86)$ & $10,04(18,30)$ & $8,09(16,50)$ & \\
\hline & \multicolumn{4}{|c|}{ \% Esclerênquima } & \\
\hline 1 & $2,25(8,56)$ & $3,35(10,42)$ & $2,15(8,39)$ & $2,76(9,56)$ & $2,63(9,23)$ \\
\hline 16 & $3,76(11,17)$ & $4,24(11,85)$ & $2,26(8,41)$ & $2,38(8,80)$ & $3,16(10,06)$ \\
\hline \multirow[t]{2}{*}{ Média } & $3,01(9,86) \mathrm{ab}$ & $3,79(11,14) \mathrm{a}$ & $2,20(8,40) \mathrm{c}$ & $2,57(9,18) b c$ & \\
\hline & \multicolumn{4}{|c|}{ \% Parênquima } & \\
\hline 1 & $45,00(42,13) \mathrm{abA}$ & $40,00(39,18) \mathrm{bA}$ & $51,53(45,87) \mathrm{aA}$ & $50,08(45,04) \mathrm{aA}$ & $46,65(43,06)$ \\
\hline 16 & $43,99(41,53) \mathrm{bA}$ & $38,59(38,40) \mathrm{bA}$ & $39,90(39,15) \mathrm{bB}$ & $54,55(47,63) \mathrm{aA}$ & $44,23(41,68)$ \\
\hline \multirow[t]{2}{*}{ Média } & $44,50(41,83)$ & $39,30(38,79)$ & $45,71(42,51)$ & $52,31(46,34)$ & \\
\hline & \multicolumn{4}{|c|}{ Espessura foliar $(\mu \mathrm{m})$} & \\
\hline 1 & $426,15 \mathrm{aA}$ & $335,10 \mathrm{bA}$ & $460,38 \mathrm{aA}$ & $443,72 \mathrm{aA}$ & 416,34 \\
\hline 16 & $348,03 \mathrm{bB}$ & $359,10 \mathrm{bA}$ & $290,30 \mathrm{bB}$ & $441,42 \mathrm{aA}$ & 359,71 \\
\hline Média & 387,09 & 347,10 & 375,34 & 442,57 & \\
\hline
\end{tabular}

Os dados originais de porcentagem foram transformados em arco seno $\sqrt{\mathrm{x}} / 100$, entre parênteses. Médias seguidas de mesma letra, minúscula na linha e maiúscula na coluna, não diferem estatisticamente entre si a 5\% de probabilidade pelo teste LSD. ${ }^{1 /}$ DAA - dias após a aplicação.

apresentou diferença estatística somente para o fator herbicida (Tabela 2). Assim, ao analisar as médias obtidas pelos herbicidas para o caractere porcentagem da epiderme adaxial, observou-se que apenas o imazapyr $(6,47 \%)$ apresentou valor inferior, em relação à testemunha (10,46\%) (Tabela 3). Da mesma forma, para a porcentagem de esclerênquima, apenas o glyphosate $(2,20 \%)$ mostrou valor inferior, em comparação à testemunha (3,01\%).

Para a primeira época de avaliação (1 DAA), o diquat foi o que proporcionou as maiores alterações anatômicas da região da nervura central do limbo foliar, com aumento da porcentagem da epiderme abaxial e do feixe vascular e diminuição da espessura foliar em relação à testemunha. Já para a segunda época de avaliação (16 DAA), o imazapyr foi o que proporcionou as maiores alterações anatômicas, com aumento da porcentagem de parênquima e da espessura foliar e diminuição da epiderme abaxial e do feixe vascular em relação à testemunha, corroborando os dados da Tabela 1.

Na Tabela 4 podem-se observar os valores médios dos caracteres anatômicos 
quantitativos da região internervural do limbo foliar das plantas de $B$. subquadripara. Verificou-se que apenas os caracteres porcentagem de epiderme adaxial e porcentagem da endoderme não apresentaram significância estatística para os fatores herbicidas e época de avaliação e a interação (Tabelas 2 e 4).

Ao 1 DAA, o diquat foi o que proporcionou as maiores alterações anatômicas da região internervural do limbo foliar, com aumento da porcentagem do feixe vascular e do esclerênquina e diminuição da espessura foliar em comparação com atestemunha. Já aos 16 DAA, o imazapyr foi o que proporcionou as maiores alterações anatômicas, com aumento da porcentagem de parênquima e da espessura foliar e diminuição da epiderme abaxial e do feixe vascular em relação à testemunha, semelhante aos resultados da região da nervura central do limbo foliar (Tabela 3).

Na Tabela 5 podem-se observar os valores médios dos caracteres anatômicos quantitativos da região do colmo das plantas de $B$. subquadripara. Verificou-se que somente os

Tabela 4 - Valores médios dos caracteres anatômicos quantitativos da região internervural do limbo foliar das plantas de $B$. subquadripara. Botucatu-SP, 2005

\begin{tabular}{|c|c|c|c|c|c|}
\hline \multirow{2}{*}{$\mathrm{DAA}^{\underline{1}}$} & \multicolumn{4}{|c|}{ Herbicida } & \multirow{2}{*}{ Média } \\
\hline & Testemunha & Diquat & Glyphosate & Imazapyr & \\
\hline & \multicolumn{4}{|c|}{$\%$ Epiderme adaxial } & \\
\hline 1 & $15,37(23,05)$ & $14,66(22,51)$ & $13,79(21,77)$ & $13,56(21,56)$ & $14,34(22,22)$ \\
\hline 16 & $15,41(23,10)$ & $14,66(22,51)$ & $14,73(22,56)$ & $14,18(22,12)$ & $14,75(22,57)$ \\
\hline \multirow[t]{2}{*}{ Média } & $15,39(23,07)$ & $14,66(22,51)$ & $14,26(22,16)$ & $13,87(21,84)$ & \\
\hline & \multicolumn{4}{|c|}{$\%$ Epiderme abaxial } & \\
\hline 1 & $4,78(12,63) \mathrm{aB}$ & $5,72(13,82) \mathrm{aA}$ & $4,81(12,64) \mathrm{aB}$ & $4,89(12,76) \mathrm{aA}$ & $5,05(12,96)$ \\
\hline 16 & $6,56(14,83)$ abA & $5,72(13,82) \mathrm{bcA}$ & $7,24(15,56) \mathrm{aA}$ & $5,15(13,10) \mathrm{cA}$ & $6,17(14,33)$ \\
\hline \multirow[t]{2}{*}{ Média } & $5,67(13,73)$ & $5,72(13,82)$ & $6,03(14,10)$ & $5,02(12,93)$ & \\
\hline & \multicolumn{4}{|c|}{$\%$ Endoderme } & \\
\hline 1 & $30,86(33,74)$ & $30,15(33,30)$ & $29,53(32,90)$ & $30,47(33,50)$ & $30,25(33,03)$ \\
\hline 16 & $29,00(32,58)$ & $30,15(33,30)$ & $29,68(33,00)$ & $30,04(33,23)$ & $29,72(33,36)$ \\
\hline \multirow[t]{2}{*}{ Média } & $29,93(33,16)$ & $30,15(33,30)$ & $29,60(32,95)$ & $30,26(33,37)$ & \\
\hline & \multicolumn{4}{|c|}{$\%$ Feixe vascular } & \\
\hline 1 & $6,73(14,80) \mathrm{bB}$ & $9,22(17,68) \mathrm{aA}$ & $7,83(16,25) \mathrm{abB}$ & $8,65(17,09)$ aA & $8,11(16,45)$ \\
\hline 16 & $10,31(18,72) \mathrm{bA}$ & $9,22(17,68) \mathrm{bcA}$ & $12,69(20,85) \mathrm{aA}$ & $8,31(16,74) \mathrm{cA}$ & $9,73(18,50)$ \\
\hline \multirow[t]{2}{*}{ Média } & $8,52(16,76)$ & $9,22(17,68)$ & $10,26(18,55)$ & $8,48(16,92)$ & \\
\hline & \multicolumn{4}{|c|}{ \% Esclerênquima } & \\
\hline 1 & $0,84(5,25) \mathrm{bB}$ & $1,16(6,17) \mathrm{aA}$ & $1,04(5,82)$ abA & $1,02(5,79) \mathrm{abA}$ & $1,01(5,76)$ \\
\hline 16 & $1,52(7,08) \mathrm{aA}$ & $1,16(6,17) \mathrm{bA}$ & $1,05(5,87) \mathrm{bcA}$ & $\begin{array}{c}0,86(5,22) \\
\mathrm{cA}\end{array}$ & $1,15(6,08)$ \\
\hline \multirow[t]{2}{*}{ Média } & $1,18(6,16)$ & $1,16(6,17)$ & $1,04(5,85)$ & $0,94(5,51)$ & \\
\hline & \multicolumn{4}{|c|}{ \% Parênquima } & \\
\hline 1 & $41,42(40,05) \mathrm{abA}$ & $39,09(38,70) \mathrm{bA}$ & $43,00(40,97) \mathrm{aA}$ & $41,41(40,05) \mathrm{abA}$ & $41,23(39,94)$ \\
\hline 16 & $37,21(37,58) \mathrm{bcB}$ & $39,09(38,70) \mathrm{abA}$ & $34,60(36,02) \mathrm{cB}$ & $41,46(40,08) \mathrm{aA}$ & $38,09(38,10)$ \\
\hline \multirow[t]{2}{*}{ Média } & $39,31(38,82)$ & $39,09(38,70)$ & $38,80(38,50)$ & $41,43(40,06)$ & \\
\hline & \multicolumn{4}{|c|}{ Espessura foliar $(\mu \mathrm{m})$} & \\
\hline 1 & $356,32 \mathrm{aA}$ & $296,53 \mathrm{bA}$ & $366,50 \mathrm{aA}$ & $346,22 \mathrm{aA}$ & 341,39 \\
\hline 16 & $268,31 \mathrm{bcB}$ & $296,53 \mathrm{bA}$ & $250,38 \mathrm{cB}$ & $344,60 \mathrm{aA}$ & 289,95 \\
\hline Média & 312,31 & 296,53 & 308,44 & 345,41 & \\
\hline
\end{tabular}

Os dados originais de porcentagem foram transformados em arco seno $\sqrt{\mathrm{x}} / 100$, entre parênteses. Médias seguidas de mesma letra, minúscula na linha e maiúscula na coluna, não diferem estatisticamente entre si a $5 \%$ de probabilidade pelo teste LSD. ${ }^{1 /}$ DAA - dias após a aplicação. 
caracteres porcentagem do feixe vascular e porcentagem de lacunas do aerênquima apresentaram interação estatística para os fatores herbicidas e época de avaliação e a interação (Tabelas 2 e 5). As maiores alterações anatômicas do colmo ocorreram aos 16 DAA, promovidas pelo diquat, que proporcionou diminuição da porcentagem do feixe vascular e da média de porcentagem de parênquima em relação à testemunha. O glyphosate aumentou a porcentagem do feixe vascular e de lacunas do aerênquima, enquanto o imazapyr aumentou a porcentagem de lacunas do aerênquima. Os demais caracteres da anatomia da região do colmo não foram alterados pelos herbicidas.

No geral, a ineficiência no controle do diquat devido a algumas plantas apresentarem início de rebrota a partir dos 10 DAA pode ser justificada pelo fato de o diquat ser um herbicida de contato e possuir baixa translocação na planta. Assim, no momento da pulverização, em algumas regiões da planta pode não ter ocorrido deposição do produto, sendo preservados caracteres anatômicos capazes de regenerar a planta (Costa et al., 2011).

O glyphosate, herbicida sistêmico que atua sobre a atividade enzimática responsável pela formação dos aminoácidos triptofano, tirosina e fenilalanina e outros produtos endógenos, apresentou alta eficácia no controle de plantas de $B$. subquadripara. Contudo, as principais alterações anatômicas do limbo foliar foram o aumento da porcentagem do feixe vascular e a diminuição da porcentagem

Tabela 5 - Valores médios dos caracteres anatômicos quantitativos da região do colmo das plantas de B. subquadripara. Botucatu-SP, 2005

\begin{tabular}{|c|c|c|c|c|c|}
\hline \multirow{2}{*}{$\mathrm{DAA}^{1 /}$} & \multicolumn{4}{|c|}{ Herbicida } & \multirow{2}{*}{ Média } \\
\hline & Testemunha & Diquat & Glyphosate & Imazapyr & \\
\hline & \multicolumn{4}{|c|}{$\%$ Epiderme } & \\
\hline 1 & $6,03(14,20)$ & $4,85(12,71)$ & $5,77(13,85)$ & $5,19(13,15)$ & $5,46(13,48) \mathrm{A}$ \\
\hline 16 & $4,73(12,56)$ & $4,47(12,16)$ & $5,05(12,98)$ & $4,57(12,32)$ & $4,70(12,50) \mathrm{B}$ \\
\hline \multirow[t]{2}{*}{ Média } & $5,38(13,38)$ & $4,66(12,44)$ & $5,41(13,41)$ & $4,88(12,73)$ & \\
\hline & \multicolumn{4}{|c|}{ \% Câmbio vascular } & \\
\hline 1 & $11,80(20,07)$ & $10,52(18,92)$ & $12,45(20,65)$ & $13,83(21,81)$ & $12,15(20,36)$ \\
\hline 16 & $17,28(24,03)$ & $11,02(19,23)$ & $19,10(25,81)$ & $12,04(20,30)$ & $14,86(22,34)$ \\
\hline \multirow[t]{2}{*}{ Média } & $14,54(22,05)$ & $10,77(19,07)$ & $15,78(23,23)$ & $12,93(21,05)$ & \\
\hline & \multicolumn{4}{|c|}{ \% Feixe Vascular } & \\
\hline 1 & $30,60(33,56) \mathrm{aA}$ & $29,69(33,01) \mathrm{aA}$ & $30,49(33,47) \mathrm{aA}$ & $30,93(33,78) \mathrm{aA}$ & $30,43(33,46)$ \\
\hline 16 & $25,74(30,42) \mathrm{bA}$ & $21,93(27,90) \mathrm{bB}$ & $34,91(36,20) \mathrm{aA}$ & $26,92(31,20) \mathrm{bA}$ & $27,38(31,43)$ \\
\hline \multirow[t]{2}{*}{ Média } & $28,17(31,99)$ & $25,81(30,46)$ & $32,70(34,83)$ & $28,93(32,49)$ & \\
\hline & \multicolumn{4}{|c|}{ \% Lacunas do aerênquima } & \\
\hline 1 & $13,04(21,15) \mathrm{aA}$ & $17,88(24,85) \mathrm{aA}$ & $11,58(19,83) \mathrm{aA}$ & $13,91(21,69) \mathrm{aA}$ & $14,10(21,88)$ \\
\hline 16 & $8,72(16,90) \mathrm{bA}$ & $13,79(21,19) \mathrm{abA}$ & $17,80(24,89) \mathrm{aA}$ & $19,92(26,28) \mathrm{aA}$ & $15,06(22,32)$ \\
\hline \multirow[t]{2}{*}{ Média } & $10,88(19,03)$ & $15,83(23,02)$ & $14,69(22,36)$ & $16,91(23,98)$ & \\
\hline & \multicolumn{4}{|c|}{ \% Parênquima } & \\
\hline 1 & $56,83(49,53)$ & $27,55(31,65)$ & $45,24(42,19)$ & $41,75(40,16)$ & $42,84(40,88) \mathrm{A}$ \\
\hline 16 & $26,38(30,73)$ & $18,28(24,70)$ & $42,29(40,54)$ & $31,23(33,91)$ & $29,55(32,47) \mathrm{B}$ \\
\hline \multirow[t]{2}{*}{ Média } & $41,60(40,13) \mathrm{a}$ & $22,91(28,18) b$ & $43,77(41,36) \mathrm{a}$ & $36,49(37,04) \mathrm{a}$ & \\
\hline & \multicolumn{4}{|c|}{ Diâmetro do caule (mm) } & \\
\hline 1 & $3.011,37$ & $2.991,60$ & $3.110,33$ & $3.115,99$ & $3.057,32$ \\
\hline 16 & $3.182,41$ & $2.691,13$ & $3.006,42$ & $2.764,48$ & $2.911,11$ \\
\hline Média & $3.096,89$ & $2.841,37$ & $3.058,37$ & $2.940,24$ & \\
\hline
\end{tabular}

Os dados originais de porcentagem foram transformados em arco seno $\sqrt{\mathrm{x}} / 100$, entre parênteses. Médias seguidas de mesma letra, minúscula na linha e maiúscula na coluna, não diferem estatisticamente entre si a $5 \%$ de probabilidade pelo teste LSD. ${ }^{1 /} \mathrm{DAA}$ - dias após a aplicação. 
de esclerênquima, principalmente na segunda época de avaliação. Esse fato, no ambiente aquático, pode ter favorecido a translocação de água e solutos pela planta e a degradação da molécula do herbicida ao longo do tempo, corroborando os resultados de controle aos 226 DAA (Tabela 1).

Já o imazapyr, um herbicida sistêmico que inibe a sintese do ácido acetolactato sintase (ALS), enzima comum no processo de biossíntese de três aminoácidos alifáticos de cadeia ramificada (valina, leucina e isoleucina), apresentou excelente eficácia no controle de plantas de $B$. subquadripara. Entretanto, as principais alterações anatômicas do limbo foliar foram o aumento da porcentagem do parênquima e da espessura foliar e a diminuição da porcentagem da epiderme abaxial, da porcentagem do feixe vascular e da porcentagem de esclerênquima, sobretudo na segunda época de avaliação. Assim, o aumento do tecido do parênquima e da espessura foliar pode ter compensado a redução dos tecidos alterados e favorecido a metabolização da molécula pela hidroxilação do anel imidazolinona para fomar ácido 2-carbamoilnicotínico, o que permitiu a regeneração da planta, confirmando os resultados de controle aos 226 DAA (Tabela 1) (Rodrigues $\&$ Almeida, 2005).

Com base nos resultados, ressalta-se que os principais caracteres anatômicos quantitativos das regiões da nervura central e internervural do limbo foliar que sofreram alterações após a aplicação dos herbicidas foram: porcentagem da epiderme abaxial, porcentagem da endoderme, porcentagem de feixe vascular, porcentagem de esclerênquima e espessura foliar; as alterações mais evidentes foram observadas na segunda época de avaliação (16 DAA). Para a região do colmo, os principais caracteres anatômicos quantitativos que sofreram alterações foram: porcentagem do feixe vascular, porcentagem de lacunas do aerênquima e porcentagem do parênquima.

Os herbicidas diquat e imazapyr promoveram o maior número de alterações nos caracteres anatômicos quantitativos das regiões da nervura central e internervural do limbo foliar e da região do colmo das plantas de $B$. subquadripara. Entretanto, todos os herbicidas permitiram rebrota das plantas. Esses resultados evidenciam que o manejo químico de plantas de $B$. subquadripara requer mais estudos de longo prazo, uma vez que essa espécie possui alta capacidade de regeneração e reprodução após a aplicação de herbicidas considerados eficientes, como o diquat, glyphosate e imazapyr.

\section{LITERATURA CITADA}

CARBONARI, C. A.; MARTINS, D; TERRA, M. A Controle de Brachiaria subquadripara e Brachiaria mutica através de diferentes herbicidas aplicados em pós-emergência. Planta Daninha, v. 21, n. 1, p. 79-84, 2003. (Edição Especial)

CARDOSO, L. R. et al. Variabilidade genética de acessos de aguapé coletados no Estado de São Paulo. Planta Daninha, v. 20, n. 1, p. 1-5, 2002. (Edição Especial)

COSTA, N. V. et al. Alterações anatômicas foliares em Eichhornia crassipes submetidas à aplicação de herbicidas Planta Daninha, v. 29, n. 1, p. 17-23, 2011

GERRITS, P. O. The application of glycol metacrylate in histotechnology: same fundamental principles. Germany: Lica Gmgh, 1991. 80 p.

HOFSTRA, D. E.; CLAYTON, J. S.; GETSINGER, K. D Evaluation of selected herbicides for the control of exotic submerged weeds in New Zealand: II. The effects of turbidity on diquat and endothall efficacy. J. Aquat. Plant Manag., v. 39, n. 1, p. $25-27,2001$.

JOHANSEN, D. A. Plant microtechnique. New York: McGrow-Hill Book, 1940. 523 p.

MARTINS, D. et al. Caracterização da comunidade de plantas aquáticas de dezoito reservatórios pertencentes a cinco bacias hidrográficas do Estado de São Paulo. Planta Daninha, v. 26, n. 1, p. $17-32,2008$

MURPHY, K. J.; BARRETT, P. R. F. Chemical control of aquatic weeds. In: PIETERSE, A. H.; MURPHY, K. J.

Aquatic weeds: the ecology and management of nuisance aquatic vegetation. Oxford: Oxford University Press, 1990 p. $136-173$

O`BRIEN, T. P.; FEDER, N.; McCULLY, M. E. Polychmofic staing of plant cellular wall by toluidine blue. Protoplasma, v. 59 , p. $368-373,1964$.

PARSONS, J. K. et al. The use 2,4-D for selective control of an early infestation of eurasian watermilfoil in loon lake, Washington. J. Aquat. Plant Manag., v. 39, n. 2, p. 117-125, 2001. 
PIMENTEL-GOMES, F. Curso de estatística

experimental. 6.ed. Piracicaba: Gráfica Binetti, 1976. 430 p.

PROCÓPIO, S. O. et al. Estudos anatômicos de folhas de plantas daninhas de grande ocorrência no Brasil. III.

Galinsoga parviflora, Crotalaria incana, Conyza bonariensis e Ipomoea cairica. Planta Daninha, v. 21, n. 1, p. 1-9, 2003.

RODRIGUES, B. N.; ALMEIDA, F. S. Guia de herbicidas. 5.ed. Londrina: 2005. 592 p.
SOCIEDADE BRASILEIRA DA CIÊNCIA DAS PLANTAS DANINHAS - SBCS. Procedimentos para instalação, avaliação e análise de experimentos com herbicidas. Londrina: 1995.42 p.

TANAKA, R. H. Eficácia de fluoridone para o controle de Egeria ssp. em caixas d'água e em represa de pequeno porte sem fluxo de água. 2001. 157 f. Dissertação (Mestrado em Ciências Agronômicas)-Faculdade de Ciências Agronômicas, Universidade Estadual de Paulista, Botucatu, 2001. 